\title{
Impact of Carbohydrate-Electrolyte Beverage Ingestion on Heart Rate Response While Climbing Mountain Fuji at $\sim 3000 \mathrm{~m}$
}

\author{
Masahiro Horiuchi, ${ }^{1}$ Junko Endo, ${ }^{1}$ Koichi Kondo, ${ }^{2}$ Tadashi Uno, ${ }^{1}$ \\ Mayuko Morikawa, ${ }^{3,4}$ and Hiroshi Nose ${ }^{3,4}$ \\ ${ }^{1}$ Division of Human Environmental Science, Mount Fuji Research Institute, Kamiyoshida 5597-1, \\ Fujiyoshida, Yamanashi 4030005, Japan \\ ${ }^{2}$ Mount Fuji Climbing School, Asahi 4-1-7, Fujiyoshida, Yamanashi 4030012, Japan \\ ${ }^{3}$ Department of Sports Medical Sciences, Shinshu University Graduate School of Medicine, Asahi 3-1-1, \\ Matsumoto, Nagano 3908621, Japan \\ ${ }^{4}$ Institute for Biomedical Sciences, Asahi 3-1-1, Matsumoto, Nagano 3908621, Japan \\ Correspondence should be addressed to Masahiro Horiuchi; mhoriuchi@mfri.pref.yamanashi.jp
}

Received 21 March 2017; Revised 31 May 2017; Accepted 7 June 2017; Published 10 July 2017

Academic Editor: Jason $\mathrm{Ng}$

Copyright ( 2017 Masahiro Horiuchi et al. This is an open access article distributed under the Creative Commons Attribution License, which permits unrestricted use, distribution, and reproduction in any medium, provided the original work is properly cited.

\begin{abstract}
We sought to investigate whether carbohydrate-electrolyte beverage ingestion reduced heart rate (HR) in twenty-three healthy young adults while climbing Mount Fuji at a given exercise intensity. Twenty-three healthy adults were randomly divided into two groups: the tap water (11 males $[\mathrm{M}]$ and 1 female $[\mathrm{F}]$ ) and the carbohydrate-electrolyte group (10 M and $1 \mathrm{~F})$. HR and activity energy expenditure (AEE) were recorded every min. The HRs for the first 30 minutes of climbing were not significantly different between the groups [121 \pm 2 beats per $\min (\mathrm{bpm})$ in the tap water and $116 \pm 3 \mathrm{bpm}$ in the carbohydrate-electrolyte]; however, HR significantly increased with climbing in the tap water group $(129 \pm 2 \mathrm{bpm})$ but showed no significant increase in the carbohydrate-electrolyte group (121 $\pm 3 \mathrm{bpm})$. In addition, body weight changes throughout two days ascending and descending on Mount Fuji were inversely related to changes in resting HR. Further, individual variation of body weight changes was suppressed by carbohydrate-electrolyte drink. Collectively, carbohydrate-electrolyte beverage intake may attenuate an increase in HR at a given AEE while mountaineering at $\sim 3000 \mathrm{~m}$ compared with tap water intake.
\end{abstract}

\section{Introduction}

Mount (Mt.) Fuji ( $\sim 3776 \mathrm{~m})$ is the highest mountain in Japan. More than 250,000 tourists climb to its peak every summer [1], but the number has been increasing since the mountain was accredited as a World Heritage Site in 2013. More than 400 tourists every year visit the clinic located at $3,000 \mathrm{~m}$ for their health issues, and $65 \%$ of them show symptoms of acute mountain sickness (AMS) [1]. Since there has been a possibility that AMS is frequently accompanied by dehydration [2], and intravenous saline infusion improves dehydration status [3], the maintenance of euhydration using appropriate beverage intake while climbing may help to prevent AMS. In addition, individual variance of exercise performance under hypoxia with hypohydration was greater compared to euhydration, suggesting that prevention of individual variance may also be important during exercise at high altitude.

Carbohydrate-electrolyte (CE) solution intake has been reported to improve thermoregulatory responses, thereby attenuating an increase in heart rate (HR) at a given exercise intensity through accelerated rehydration during sports events at the sea level compared with tap water (TW) [47]. However, there have been few studies that examine this issue during mountaineering because there was no device to measure exercise intensity at high altitude.

Recently, calorimeters equipped with triaxial accelerometers and barometers (to measure kinetic and potential energies, resp.) have become commercially available $[8,9]$. Using this equipment, we were able to evaluate the effects 
TABLE 1: Physical characteristics of subjects and physiological responses between two groups.

\begin{tabular}{|c|c|c|c|}
\hline & $\begin{array}{c}\text { TW } \\
n=12(11 \text { men, } 1 \text { woman })\end{array}$ & $\begin{array}{c}\text { CE } \\
n=11(10 \text { men, } 1 \text { woman })\end{array}$ & $P$ value \\
\hline Age, years & $28.4 \pm 1.9$ & $29.0 \pm 1.5$ & 0.810 \\
\hline Height, cm & $173.6 \pm 1.7$ & $171.6 \pm 2.9$ & 0.559 \\
\hline Weight, kg & $66.4 \pm 2.9$ & $66.4 \pm 2.8$ & 0.992 \\
\hline BMI, $\mathrm{kg}\left(\mathrm{m}^{2}\right)^{-1}$ & $22.0 \pm 0.8$ & $22.5 \pm 0.7$ & 0.616 \\
\hline Resting HR, beats $\min ^{-1}$ & $92 \pm 2$ & $89 \pm 3$ & 0.404 \\
\hline $\mathrm{HR}_{\text {peak }}$, beats $\min ^{-1}$ & $149 \pm 4$ & $142 \pm 3$ & 0.134 \\
\hline $\mathrm{WV்O}_{2}, \mathrm{ml} \mathrm{kg} \mathrm{min}^{-1}$ & $25.6 \pm 1.0$ & $23.8 \pm 0.7$ & 0.162 \\
\hline $\mathrm{EV}_{2 \text { peak }}, \mathrm{ml} \mathrm{kg} \mathrm{min}^{-1}$ & $37.0 \pm 2.4$ & $36.5 \pm 1.9$ & 0.870 \\
\hline $\mathrm{SpO}_{2 \text { nadir }}, \%$ & $86.6 \pm 2.6$ & $86.9 \pm 2.6$ & 0.767 \\
\hline Body weight changes, $g$ & $-154 \pm 193$ & $22 \pm 106$ & 0.441 \\
\hline Total amount of fluid intake, $\mathrm{ml}$ & $1280 \pm 113$ & $1127 \pm 100$ & 0.327 \\
\hline Total amount of energy intake, $\mathrm{kJ}$ & $5266 \pm 420$ & $5506 \pm 314$ & 0.656 \\
\hline
\end{tabular}

Values are mean \pm standard deviation (SD). TW, tap water group; CE, carbohydrate-electrolyte solution group; BMI, body mass index; $\mathrm{HR}_{\text {peak }}$ and WVंO ${ }_{2 \text { peak }}$, peak heart rate and peak aerobic capacity determined by the graded walking test; $\mathrm{EVO}_{2 \text { peak }}$, peak aerobic capacity estimated from the age-predicted maximal heart rate; $\mathrm{SpO}_{2}$, arterial $\mathrm{O}_{2}$ saturation.

of beverage intake on HR at a given intensity during mountaineering [8].

In the current study, we measured HR and activity energy expenditure (AEE) in young adults while climbing Mt. Fuji to a $3000 \mathrm{~m}$ altitude, during which they drank CE or TW freely depending on their assigned test group. Then, we compared $\mathrm{HR}$ responses at a given intensity between the groups. We hypothesized that HR at a given intensity would be reduced in the CE group compared with the TW group during climbing mountain at high altitude. It was also hypothesized that $\mathrm{CE}$ ingestion can prevent individual variance of body weight loss as an indirect indicator of dehydration status.

\section{Methods}

2.1. Participants. Twenty-three healthy adult participants were randomly divided into two groups: the TW group $(n=12,11$ males $[\mathrm{M}]$ and 1 female $[\mathrm{F}])$, which consumed TW ( 0 kcal energy, $0 \mathrm{~g}$ carbohydrate, protein, fat, sodium, potassium, calcium, and magnesium), and the CE group ( $n=$ $11,10 \mathrm{M}$ and $1 \mathrm{~F}$ ), which consumed a CE solution $(25 \mathrm{kcal}$ energy, $6.2 \mathrm{~g}$ carbohydrate, $0 \mathrm{~g}$ protein, $0 \mathrm{~g}$ fat, $49 \mathrm{mg}$ sodium, $20 \mathrm{mg}$ potassium, $2 \mathrm{mg}$ calcium, and $0.6 \mathrm{mg}$ of magnesium per $100 \mathrm{ml}$ ). Notably, we did not explain the differences in nutrient composition between TW and CE solution, meaning that the subjects could know only differential taste. All subjects were free from any cardiovascular diseases and have not been engaging in regular physical activities. Additionally, this was the first attempt for all subjects to climb Mt. Fuji, and none of the subjects were exposed to an altitude higher than $1500 \mathrm{~m}$ within 6 months prior to the study. All the procedures were approved by the institutional ethical committee according to the guidelines of the Declaration of Helsinki. The physical characteristics of the participants are shown in Table 1.
2.2. Procedure. The participants arrived at the parking area by car at 13:00 on July 6, 2014 to climb Mt. Fuji (2305 m) after consuming light lunch $\sim 1 \mathrm{~h}$ before their arrival. After they emptied their bladders, we measured their body weight with their clothes and boots on using a $50 \mathrm{~g}$ resolution scale (UC321, A\&D Instruments, Tokyo, Japan). We also separately measured the body weight of the participants in the nude, which excluded the weight of their clothes, boots, backpacks (weighing $\sim 7 \mathrm{~kg}$ ), jackets, sweaters, snacks, and water bottles.

Then, to estimate maximal aerobic capacity, the participants underwent a graded walking test without their backpacks. Briefly, after a baseline measurement at rest in the standing position for $3 \mathrm{~min}$, participants walked for $3 \mathrm{~min}$ on flat and paved areas at 3 graded subjective velocities (slow, moderate, and fast), during which AEE was measured with a calorie meter equipped with a triaxial accelerometer and barometer (JD Mate, Kissei Comtec, Matsumoto, Japan) fastened on the left side of their waists. Heart rate (HR) was measured with a commercial wearable HR monitor (RS 800CX, Polar Electro Japan, Tokyo, Japan) with every $5 \mathrm{sec}$ and calculated into every 1-min data.

Oxygen consumption $\left(\dot{\mathrm{VO}}_{2}\right)$ rates during the tests were determined from the values of a triaxial accelerometer and barometer according to the equation reported previously $[8,9]$. We determined the peak aerobic capacity for walking $\left(\mathrm{WVO}_{2 \text { peak }}\right.$ ) from the last consecutive three values of fast walking and the adopted peak $\mathrm{HR}\left(\mathrm{HR}_{\text {peak }}\right)$ at $\mathrm{WV}_{2 \text { peak }}$. Since $\mathrm{HR}_{\text {peak }}$ was lower than the age-predicted maximal $\mathrm{HR}$, that is, 220 -age, we estimated $\dot{V O}_{2 \text { peak }}\left(\mathrm{EVO}_{2 \text { peak }}\right)$ from the relationship between $\mathrm{HR}$ and $\dot{\mathrm{VO}}_{2}$ for 9 min by extrapolating $\mathrm{HR}$ to the age-predicted maximal HR during the test. $\mathrm{WVO}_{2 \text { peak }}$ and $\mathrm{EVO}_{2 \text { peak }}$ were presented as $\mathrm{ml} \mathrm{min}^{-1}$ per body weight in the nude $(\mathrm{kg})$, assuming that the weight of the clothes worn by the participants during the tests was $\sim 2 \mathrm{~kg}$. 


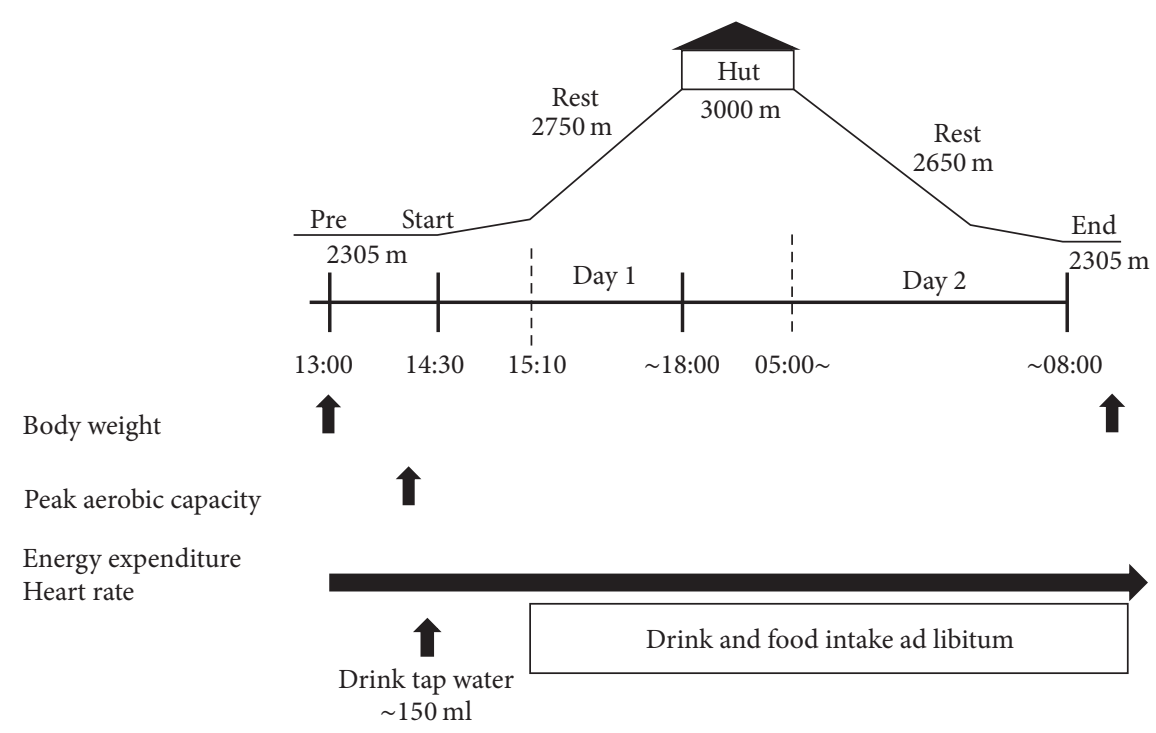

FIgURE 1: Profile of the present study. Participants consumed tap water or a carbohydrate-electrolyte beverage freely throughout the two days of the study except for the first $40 \mathrm{~min}$ before beginning to climb up the mountain on the first day, during which time we measured their body weight and peak aerobic capacity. In addition, we measured their energy expenditure and heart rate continuously while climbing up and down the mountain. Then, after climbing down the mountain, we measured body weight again. The measurements are shown in the procedure of the text.

As shown in Figure 1, after the measurements of 9 min of graded walking test, the participants were allowed to drink a tap water $\sim 150 \mathrm{ml}$, began to climb the mountain at $\sim 14: 30$, reached a lodge $(\sim 3000 \mathrm{~m})$ at $\sim 18: 00$, rested at the altitude about $\sim 2750 \mathrm{~m}$, stayed overnight at the hut, started to climb down the mountain at $\sim 05: 00$ the next morning with a short period rest $(2650 \mathrm{~m})$, and returned to the parking area $(2305 \mathrm{~m})$ at $\sim 08: 00$. Throughout two days, trekking, the party of subjects ascended and descended together. During the period, excluding the stay at the lodge, $\mathrm{HR}$ and $\mathrm{AEE}$ were recorded every min. To determine AEE, we calculated $\mathrm{VO}_{2}$ by multiplying a sum of kinetic and potential energies (measured by accelerometry and barometry, resp.) with a sum of body, clothing, shoes, and baggage weight according to the equation reported previously [8]. Then, the $\dot{\mathrm{VO}}_{2}$ value was converted to $\mathrm{kJ}$ based on a previous study [8,9]. Immediately after returning to the parking area, we asked participants to empty their bladders and measured their body weights by $50 \mathrm{~g}$ scales, in the nude as we did before their climbing (UC-321, A\&D, Tokyo, Japan). Throughout the mountaineering, participants were allowed to eat freely including lunch, snacks, drinks (either TW or CE depending on their assigned group), and dinner at the lodge prepared by us; their consumption amounts were recorded. As it has been reported that it took $\sim 30 \mathrm{~min}$ until an observation of homogeneously distributed body fluid after drinking water [10], the subjects were asked not to take any drink or foods during this period. Thus, we confirmed no drink or foods during the first 40 min of climbing as well as no evacuation throughout two days of trekking. Their total energy intake and the nutritional composition of their consumed food throughout mountaineering were calculated using a software package (Excel Eiyo-kun, Kenpakusha Co.,
Ltd., Tokyo, Japan) [8]. The periods when AEE was less than $15 \%$ of $\mathrm{VO}_{2 \text { peak }}$ obtained from the 9-min graded walking test were regarded as resting periods according to a previous study [8].

Arterial $\mathrm{O}_{2}$ saturation $\left(\mathrm{SpO}_{2}\right)$ was measured by pulse finger oximeter (MMI SB-100, Muranaka Medical Instruments Co. Ltd., Osaka, Japan). Symptoms of acute mountain sickness (AMS) were also evaluated by the Lake Louise Questionnaire (LLQ) scoring system and the criteria for AMS were defined as follows: LLQ was $\geqq 3$ with headache [11]. Values of $\mathrm{SpO}_{2}$ and LLQ score were assessed before ascending $(2305 \mathrm{~m})$, at rest during climbing $(2750 \mathrm{~m})$, at the hut before sleep and after wake-up $(3000 \mathrm{~m})$, and after descending, respectively. Then, the nadir $\left(\mathrm{SpO}_{2}\right)$ and the highest score (AMS) were taken as indices of hypoxemia and severity of AMS.

2.3. Statistical Analysis. The data are expressed as the mean \pm standard deviation (SD). A commercial statistical software package was used for all the analyses (Sigma Stat ver. 3.5, Hulinks, Chicago, IL, USA). An unpaired $t$-test was used to examine the significant differences in the physical characteristics, dietary data, and all the physiological values of the participants before climbing the mountain between the groups (Table 1). A two-way (groups $\times$ time) analysis of variance for repeated measures was used to examine the significant effects of group (TW and CE) and time (the first and last 30 min of climbing on the first day) on AEE and HR and their interactive effects (Figure 2). A Bonferroni post hoc test was conducted when any $F$ values are $P<0.05$, for further analysis. A Chi-square tests were used to assess numbers of participant's distribution with or without AMS. Pearson correlation coefficient was used to predict a relation between changes in 


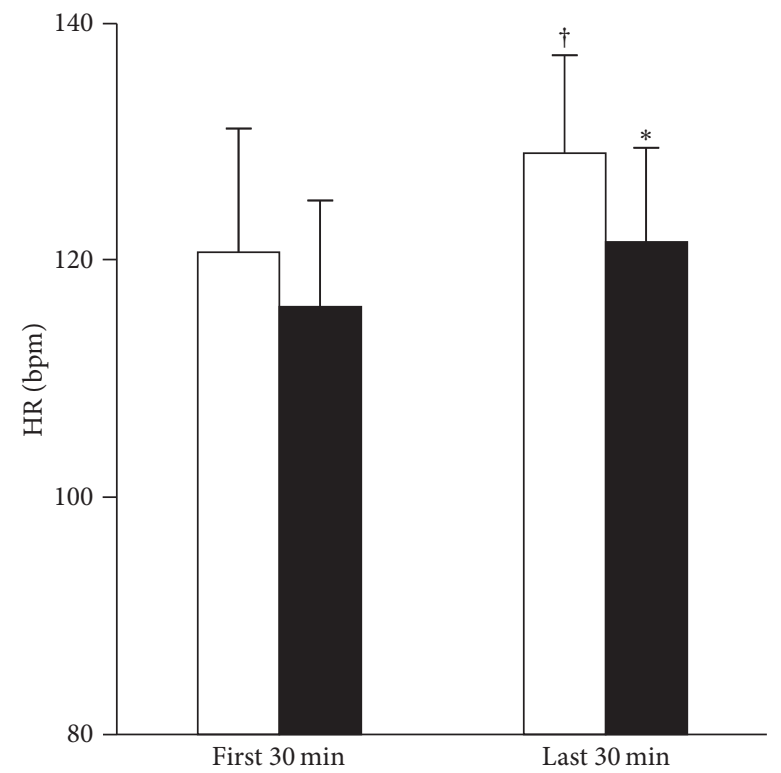

(a)

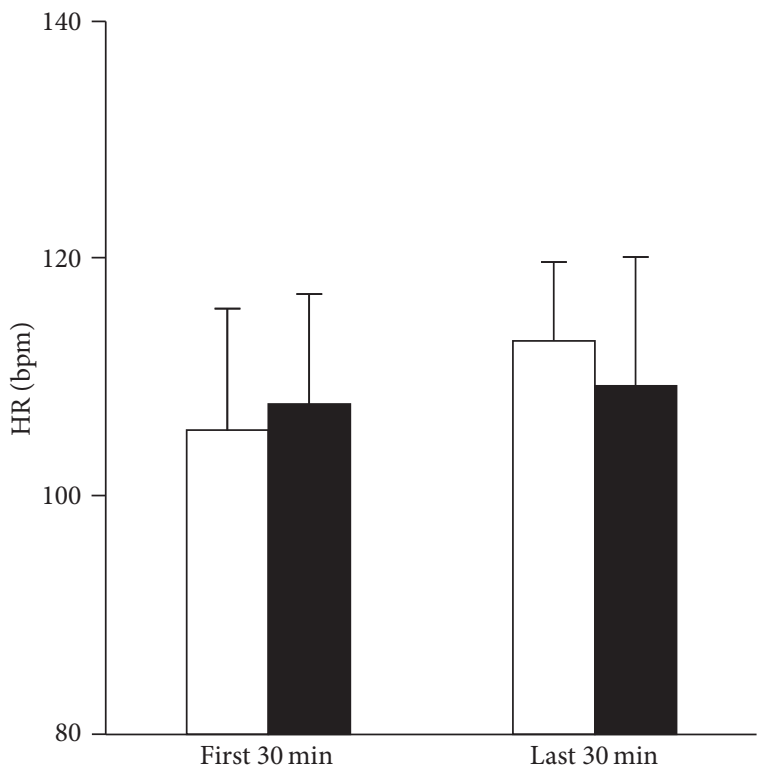

(c)

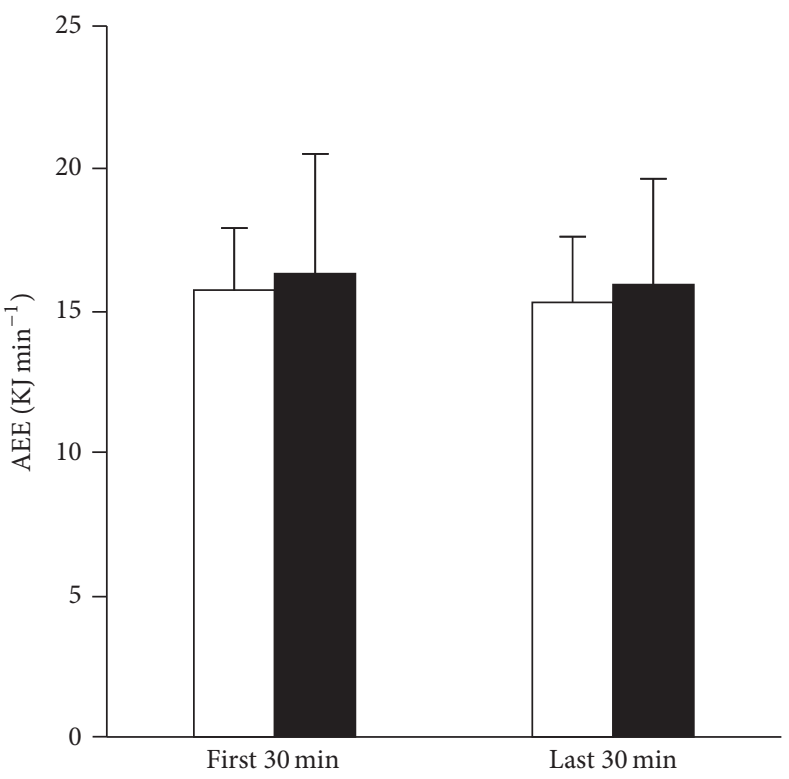

(b)

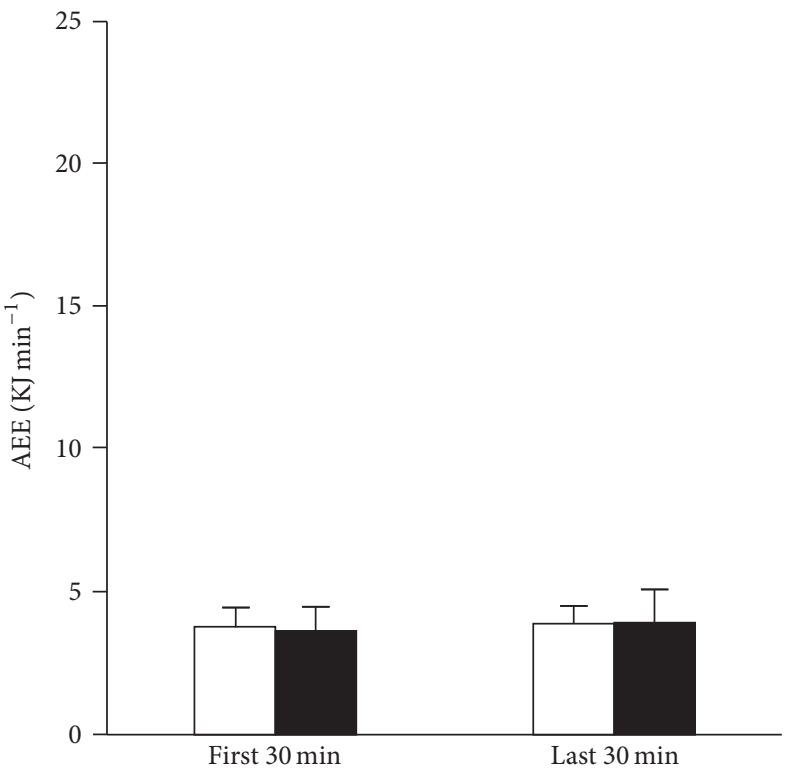

(d)

FIGURE 2: Heart rate (HR) and activity energy expenditure (AEE) for the first and last 30 min of climbing of the total 210 min during exercise ( $a$ and $b$ ) and at rest ( $c$ and d) on the first day. The means and standard deviation bars for the 12 participants in the TW group and those for the 11 participants in the CE group are shown. White bars indicate the TW, and black bars indicate the CE group, respectively. ${ }^{*} P<0.05$ between the TW and CE groups within the last 30 min of climbing. ${ }^{\dagger} P<0.05$ between the first and last 30 min of climbing within the TW group.

body weight and HR throughout two days of trekking. A $P$ value less than 0.05 was used as statistical significance.

\section{Results}

Table 1 shows the physical characteristics, $\mathrm{HR}$ at rest, $\mathrm{HR}_{\text {peak }}$, $\mathrm{WV}_{2}$, and $\mathrm{EVIO}_{2 \text { peak }}$ of the participants during the walking test before climbing the mountain. Nadir values of $\mathrm{SpO}_{2}$, individual body weight changes between preascending and postdescending, and a total amount of fluid and energy intake throughout two days were also shown in Table 1. There were no significant differences in the variables between the groups. Similarly, there are no significant differences in detailed nutrients of meals on days 1 and 2 between groups. In regard to nutrients of drinks, although they are natural, amounts of carbohydrate and sodium of CE group were greater on both days, while amounts of protein and fat of both groups are zero (Table 2). 
TABLE 2: Detailed nutrients in meals and drink on days 1 and 2 between TW and CE group.

\begin{tabular}{|c|c|c|c|}
\hline & $\begin{array}{c}\text { TW } \\
n=12(11 \text { men, } 1 \text { woman })\end{array}$ & $\begin{array}{c}\text { CE } \\
n=11 \text { (10 men, } 1 \text { woman })\end{array}$ & $P$ value \\
\hline \multicolumn{4}{|l|}{ Day 1} \\
\hline \multicolumn{4}{|l|}{ Meals } \\
\hline Protein, $g$ & $26 \pm 4$ & $24 \pm 4$ & 0.330 \\
\hline Fat, g & $25 \pm 12$ & $21 \pm 9$ & 0.420 \\
\hline Carbohydrate, g & $169 \pm 45$ & $151 \pm 23$ & 0.236 \\
\hline Sodium, mg & $1755 \pm 276$ & $1766 \pm 283$ & 0.928 \\
\hline \multicolumn{4}{|l|}{ Drink } \\
\hline Protein, g & 0 & 0 & - \\
\hline Fat, g & 0 & 0 & - \\
\hline Carbohydrate, g & 0 & $68 \pm 21$ & - \\
\hline Sodium, mg & 0 & $500 \pm 154$ & - \\
\hline \multicolumn{4}{|l|}{ Day 2} \\
\hline \multicolumn{4}{|l|}{ Meals } \\
\hline Protein, $\mathrm{g}$ & $4 \pm 1$ & $4 \pm 1$ & 0.293 \\
\hline Fat, $\mathrm{g}$ & $3 \pm 2$ & $4 \pm 2$ & 0.754 \\
\hline Carbohydrate, g & $24 \pm 11$ & $25 \pm 9$ & 0.720 \\
\hline Sodium, mg & $248 \pm 79$ & $307 \pm 105$ & 0.136 \\
\hline \multicolumn{4}{|l|}{ Drink } \\
\hline Protein, g & 0 & 0 & - \\
\hline Fat, $g$ & 0 & 0 & - \\
\hline Carbohydrate, g & 0 & $7 \pm 3$ & - \\
\hline Sodium, mg & 0 & $52 \pm 19$ & - \\
\hline
\end{tabular}

Values are mean \pm SD. Note that "-" marks indicate without statistical analysis as TW does not contain all nutrients and CE does not contain "protein" and "fat."

Figures 2(a) and 2(b) show HR and AEE while climbing to the lodge for the first and last 30 min of the first day. Although AEE did not change from the first to the last $30 \mathrm{~min}$ of climbing in either group $(P>0.05)$, HR in the TW group for the first $30 \mathrm{~min}\left(121 \pm 2\right.$ beats $\left.\mathrm{min}^{-1}\right)$ significantly increased for the last $30 \mathrm{~min}\left(129 \pm 2\right.$ beats $\left.\mathrm{min}^{-1}, P=0.002\right)$, whereas $\mathrm{HR}$ in the CE group did not reach statistical differences between first $30 \mathrm{~min}\left(116 \pm 3\right.$ beats $\left.\mathrm{min}^{-1}\right)$ and last $30 \mathrm{~min}$ (121 \pm 3 beats $\min ^{-1}, P>0.05$ ). In addition, HR in the TW group was significantly higher than those in the CE group for the last $30 \mathrm{~min}(P=0.031)$. As shown in Figures $2(\mathrm{c})$ and $2(\mathrm{~d})$, there was no significant difference in resting periods during ascending, that is, AEE less than $15 \%$ of $\mathrm{VO}_{2 \text { peak }}$, $\mathrm{HR}$, or $\mathrm{AEE}$ between the first and last $30 \mathrm{~min}$ of exercise or between the TW group and the CE group $(P>0.05$, resp.).

The average HR and AEE while descending on the second day were $105 \pm 12$ beats $\mathrm{min}^{-1}$ and $7.61 \pm 1.23 \mathrm{~kJ} \mathrm{~min}^{-1}$ in the TW group and $106 \pm 12$ beats $\mathrm{min}^{-1}$ and $7.23 \pm 1.02 \mathrm{~kJ} \mathrm{~min}^{-1}$ in the CE group, respectively, showing no significant difference between the groups $(P>0.05$, resp.).

Figure 3 shows the relationship between the changes in body weight and HR at resting condition from the values before ascending on the first day to the values after descending on the second day. We found that body weight changes significantly correlated with changes in HR at resting condition when the data were pooled from the two groups $\left(R^{2}=0.250, n=23, P=0.015\right)$. In addition, although

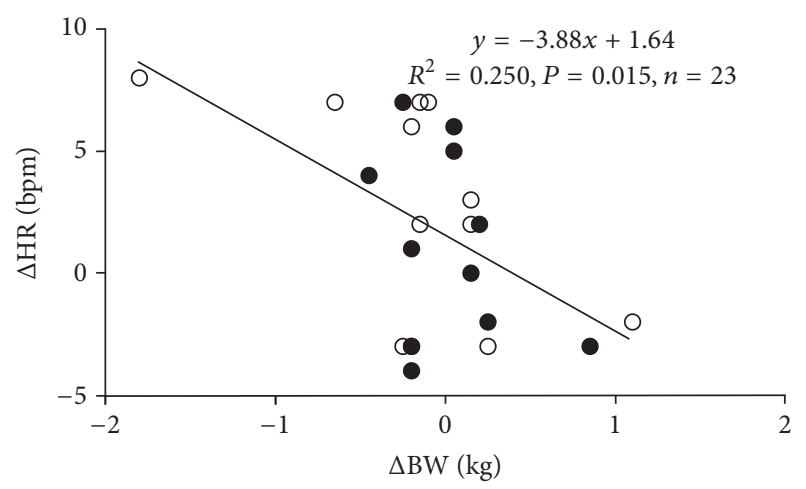

FIGURE 3: Relationship between changes in body weight and HR when the data are pooled. Changes in these values are calculated by the difference between at rest before ascending and after descending. Open circles indicate the TW and closed circles indicate the CE group.

the changes in body weight were $-154 \pm 193 \mathrm{~g}$ in the TW group and $22 \pm 106 \mathrm{~g}$ in the CE group (see Table 1) with no significant difference in mean values between groups $(P=0.441)$, the standard deviation (SD) was significantly lower in the CE group than in the TW group $(F[11,12]=$ 3.581, $P<0.01$ ). Despite this significance, the change in HR was $2.6 \pm 1.3$ beats $\mathrm{min}^{-1}$ in the TW group and $1.2 \pm$ 1.2 beats $\mathrm{min}^{-1}$ in the $\mathrm{CE}$ group, which shows no difference 
in the $\operatorname{SD}(F[11,12]=1.261 ; P>0.05)$ or mean values $(P=0.432)$.

The numbers of subjects who reached the criteria of symptoms of AMS were 3 of 11 in the CE groups (27.2\%) and 5 of 12 in the TW group (41.7\%) with no statistical differences in variance by Chi-square test $(P>0.05)$.

\section{Discussion}

In the present study, we found that (1) CE ingestion, more than TW ingestion, attenuated an increase in $\mathrm{HR}$ at a given exercise intensity during the last $30 \mathrm{~min}$ of climbing on the first day, (2) the greater body weight loss after two days of climbing caused a greater increase in resting HR, and (3) the interindividual changes in body weight after two days of ascending and descending were within a more narrow range of the variation in the CE group than in the TW group.

The detailed mechanism of the attenuated increase in HR for the last $30 \mathrm{~min}$ of climbing on the first day in the $\mathrm{CE}$ group remains unknown; however, it has been suggested that $\mathrm{CE}$ ingestion accelerates the recovery of dehydration due to a higher retention of the consumed fluid in the extracellular fluid/plasma volumes while sweating, which, otherwise, suppresses cutaneous vasodilation via baroreflexes, reduces heat dissipation, and increases body temperature, which then increases HR by directly stimulating the cardiac pacemaker $[12,13]$. Thus, the attenuated increase in $\mathrm{HR}$ due to $\mathrm{CE}$ ingestion might be caused by the attenuated increase in body temperature with a greater recovery of plasma volume [4]. Additionally, previous animal experiments demonstrated that insulin binds to various segments of nephrons to accelerate the renal $\mathrm{Na}^{+}$reabsorption rate $[14,15]$. This may indicate that insulin secretion with carbohydrate intake in meals, for example, the CE solution that is used in the present study, would accelerate $\mathrm{Na}^{+}$and body fluid recovery to attenuate voluntary dehydration. Although speculative, lower $\mathrm{HR}$ in the CE groups may be accounted for these effects of carbohydrate and sodium. Because the increase in HR during exercise is known to correlate with the rating of perceived exertion [16], the participants in the CE group likely felt less strain compared with those in the TW group even though they climbed the mountain at the same AEE and speed.

We found no significant difference in $\mathrm{HR}$ and $\mathrm{AEE}$ between groups while climbing down the mountain on the second day, probably caused by less dehydration due to the shorter period and lower intensity of exercise than on the first day; however, there was a significant correlation between the changes in HR and body weight (Figure 3), suggesting that even a small amount of dehydration increases $\operatorname{HR}[17,18]$. In addition, the smaller range of interindividual variations in body weight loss in the CE group than in the TW group suggests that CE ingestion recovers plasma volume at a higher probability than TW ingestion. It should be noted that one participant showed a marked body weight reduction and HR increase, resulting in a considerable effect on the significant relationship (Figure 3). However, it may be difficult to detect whether the values of this participant are outlier or not. In addition, a previous laboratory study reported that hypoxic exposure with hypohydration caused a greater individual variance in physiological responses compared to normoxic condition and/or euhydration status [2]. Although future studies should be required with a larger sample size, we analyzed the data using all participants. Since we assessed body weight only before and after descending, other potential factors that may affect body weight changes, such as regulatory systems of body fluid, including reninangiotensin-aldosterone system, and arginine vasopressin should be considered $[3,19]$. However, we tried to compare body weight and HR changes at the same altitude, that is, at the 5th station $\sim 2305 \mathrm{~m}$ as we sought to rule out effects of different altitude, particularly, HR changes even at resting condition. Thus, the maintenance of euhydration using fluid ingestion may be useful to prevent an increase in HR during mountaineering, and CE ingestion is more recommendable than TW ingestion to attain the desired purpose.

We did not find any differences in symptoms of AMS and $\mathrm{SpO}_{2}$ between groups. As AMS is related to hypoxemia, that is, lower $\mathrm{SpO}_{2}$ [20-22], no differences in $\mathrm{SpO}_{2}$ between groups may less affect symptoms of AMS between groups though future studies on how CE drinking may affect these symptoms and/or physiological responses should be warranted.

There are several methodological considerations to interpret our results. First, in addition to relative small sample sizes in this study, we recruited different subject's group, so, the effect of different group on physiological responses could not be completely ruled out. However, as it was impossible to control environmental conditions on the field study, we decided to conduct this study for different group on the same day. Furthermore, since there are no differences in physical characteristics and cardiorespiratory variables, our main conclusions may not be strongly affected. Second, each subject consumed fluids and food ad libitum; thus it should be noted to consider other potential effects, for example, energy intake in both fluids and foods and evacuation. However, we confirmed that participants did not evacuate and their total amount of fluids and energy intake showed no differences between groups. Finally, to clarify the underlying mechanisms and potential effect for preventing AMS, though we must acknowledge future study is required, our results may have a potential role for climbers to ingest appropriate drink.

\section{Conclusions}

TW ingestion significantly increased in HR during last $30 \mathrm{~min}$ of climbing compared to the first $30 \mathrm{~min}$, while CE ingestion suppressed an increase in $\mathrm{HR}$ at a given exercise intensity more effectively. Thus, CE ingestion might be an appropriate strategy to decrease the cardiovascular strain during mountaineering.

\section{Conflicts of Interest}

The authors declare that they have no conflicts of interest regarding the publication of this work. 


\section{Acknowledgments}

The authors thank the subjects who participated in this study. They thank all the participants for their time and effort. They also thank Mr. Takeshi Moto for recruiting and scheduling participants and Dr. Shin Akatsuka, Mrs. Eriko Yamamoto, and Dr. Hirokazu Shimodaira for their assistance in collecting data. This work was financially supported by a Grant-in-Aid for Japan Society for the Promotion of Science (JSPS: no. 26440268JP to Masahiro Horiuchi).

\section{References}

[1] "Ministry of the Environment Official Website [Internet]. Japan: Ministry of the Environment," 2015, http://www.env.go.jp/park/ fujihakone/data/fuji_tozansha.html.

[2] J. W. Castellani, S. R. Muza, S. N. Cheuvront et al., "Effect of hypohydration and altitude exposure on aerobic exercise performance and acute mountain sickness," Journal of Applied Physiology, vol. 109, no. 6, pp. 1792-1800, 2010.

[3] H. Nose, G. W. Mack, X. Shi, K. Morimoto, and E. R. Nadel, "Effect of saline infusion during exercise on thermal and circulatory regulations," Journal of Applied Physiology, vol. 69, no. 2, pp. 609-616, 1990.

[4] J. K. W. Lee, A. Q. X. Nio, W. H. Ang, L. Y. L. Law, and C. L. Lim, "Effects of ingesting a sports drink during exercise and recovery on subsequent endurance capacity," European Journal of Sport Science, vol. 11, no. 2, pp. 77-86, 2011.

[5] R. J. Maughan, L. R. Bethell, and J. B. Leiper, "Effects of ingested fluids on exercise capacity and on cardiovascular and metabolic responses to prolonged exercise in man," Experimental Physiology, vol. 81, no. 5, pp. 847-859, 1996.

[6] S. M. Shirreffs, L. F. Aragon-Vargas, M. Keil, T. D. Love, and S. Phillips, "Rehydration after exercise in the heat: A comparison of 4 commonly used drinks," International Journal of Sport Nutrition and Exercise Metabolism, vol. 17, no. 3, pp. 244-258, 2007.

[7] S. H.-S. Wong and Y. Chen, "Effect of a carbohydrate-electrolyte beverage, lemon tea, or water on rehydration during short-term recovery from exercise," International Journal of Sport Nutrition and Exercise Metabolism, vol. 21, no. 4, pp. 300-310, 2011.

[8] M. Shimizu, K. Miyagawa, S. Iwashita et al., "Energy expenditure during 2-day trail walking in the mountains $(2,857 \mathrm{~m})$ and the effects of amino acid supplementation in older men and women," European Journal of Applied Physiology, vol. 112, no. 3, pp. 1077-1086, 2012.

[9] T. Yamazaki, H. Gen-No, Y.-I. Kamijo, K. Okazaki, S. Masuki, and H. Nose, "A new device to estimate VO2 during incline walking by accelerometry and barometry," Medicine and Science in Sports and Exercise, vol. 41, no. 12, pp. 2213-2219, 2009.

[10] H. Nose, G. W. Mack, X. Shi, and E. R. Nadel, "Shift in body fluid compartments after dehydration in humans," Journal of Applied Physiology, vol. 65, no. 1, pp. 318-324, 1988.

[11] R. C. Roach, P. Bartsch, P. H. Hackett, and O. Oelz, "The Lake Louise acute mountain sickness scoring system," in Hypoxia and Molecular Medicine, J. R. Sutton, G. Coates, C. S. Houston, and V. T. Burlington, Eds., pp. 272-274, Queen City Printers, 1993.

[12] J. González-Alonso, R. Mora-Rodríguez, P. R. Below, and E. F. Coyle, "Dehydration markedly impairs cardiovascular function in hyperthermic endurance athletes during exercise," Journal of Applied Physiology, vol. 82, no. 4, pp. 1229-1236, 1997.
[13] J. D. Trinity, M. D. Pahnke, J. F. Lee, and E. F. Coyle, "Interaction of hyperthermia and heart rate on stroke volume during prolonged exercise," Journal of Applied Physiology, vol. 109, no. 3, pp. 745-751, 2010.

[14] O. Ito, Y. Kondo, N. Takahashi et al., "Insulin stimulates $\mathrm{NaCl}$ transport in isolated perfused MTAL of Henle's loop of rabbit kidney," American Journal of Physiology-Renal Fluid and Electrolyte Physiology, vol. 267, no. 2, pp. F265-F270, 1994.

[15] B. Mandon, E. Siga, D. Chabardes, D. Firsov, N. Roinel, and C. De Rouffignac, "Insulin stimulates $\mathrm{Na}+, \mathrm{Cl}-, \mathrm{Ca} 2+$, and $\mathrm{Mg} 2+$ transports in TAL of mouse nephron: Cross-potentiation with AVP," American Journal of Physiology - Renal Fluid and Electrolyte Physiology, vol. 265, no. 3, pp. F361-F369, 1993.

[16] G. Borg, P. Hassmén, and M. Lagerström, "Perceived exertion related to heart rate and blood lactate during arm and leg exercise," European Journal of Applied Physiology and Occupational Physiology, vol. 56, no. 6, pp. 679-685, 1987.

[17] M. S. Ganio, J. E. Wingo, C. E. Carroll, M. K. Thomas, and K. J. Cureton, "Fluid ingestion attenuates the decline in VO2peak associated with cardiovascular drift," Medicine and Science in Sports and Exercise, vol. 38, no. 5, pp. 901-909, 2006.

[18] M. T. Hamilton, J. Gonzalez-Alonso, S. J. Montain, and E. F. Coyle, "Fluid replacement and glucose infusion during exercise prevent cardiovascular drift," Journal of Applied Physiology, vol. 71, no. 3, pp. 871-877, 1991.

[19] Y.-I. Kamijo, S. Ikegawa, Y. Okada et al., "Enhanced renal Na + reabsorption by carbohydrate in beverages during restitution from thermal and exercise-induced dehydration in men," American Journal of Physiology - Regulatory Integrative and Comparative Physiology, vol. 303, no. 8, pp. R824-R833, 2012.

[20] P. Erba, S. Anastasi, O. Senn, M. Maggiorini, and K. E. Bloch, "Acute mountain sickness is related to nocturnal hypoxemia but not to hypoventilation," European Respiratory Journal, vol. 24, no. 2, pp. 303-308, 2004.

[21] Y. Liu, J. Zhang, X. Gao et al., "Correlation between blood pressure changes and AMS, sleeping quality and exercise upon high-altitude exposure in young Chinese men," Military Medical Research, vol. 1, p. 19, 2014.

[22] H. Nespoulet, B. Wuyam, R. Tamisier et al., "Altitude illness is related to low hypoxic chemoresponse and low oxygenation during sleep," European Respiratory Journal, vol. 40, no. 3, pp. 673-680, 2012. 

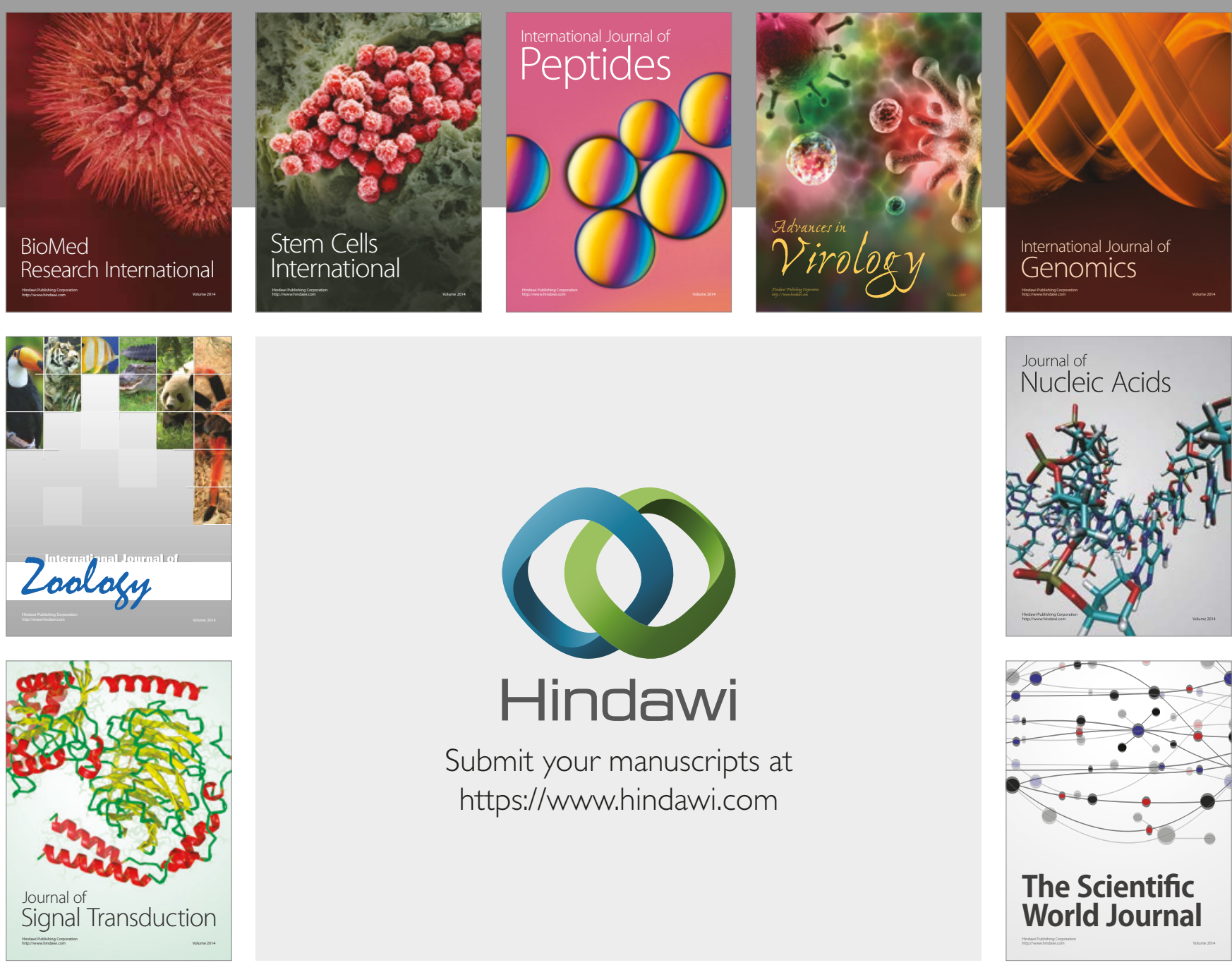

Submit your manuscripts at

https://www.hindawi.com
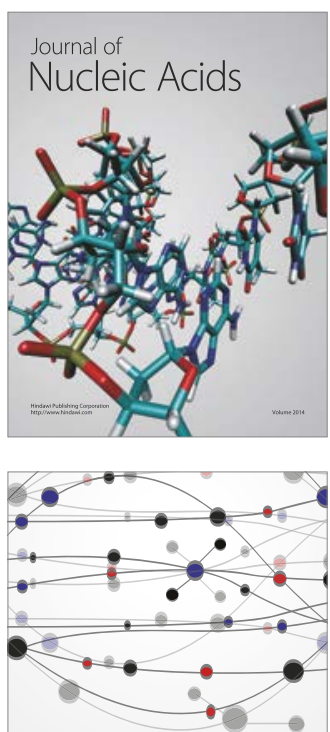

The Scientific World Journal

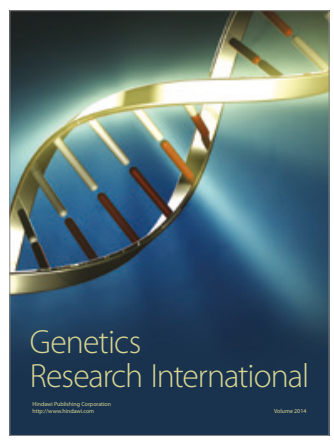

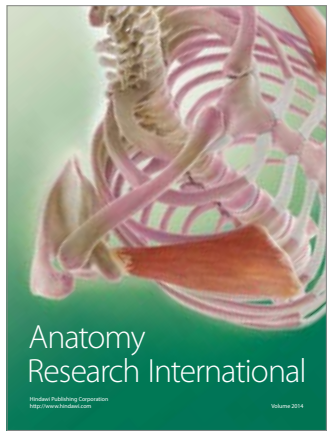

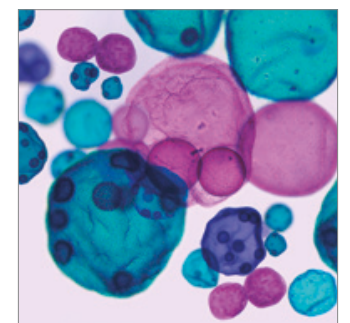

International Journal of Microbiology
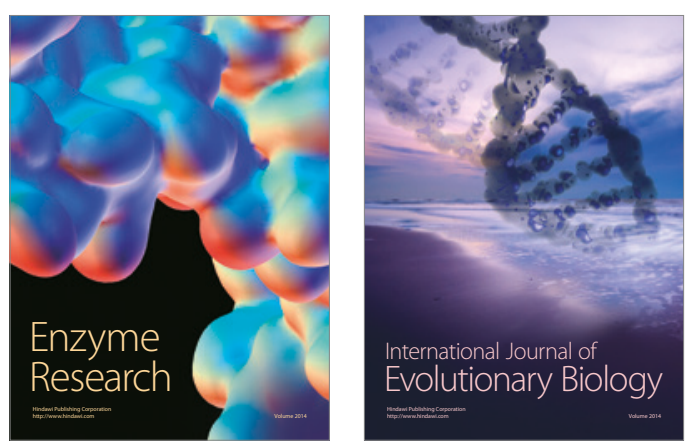
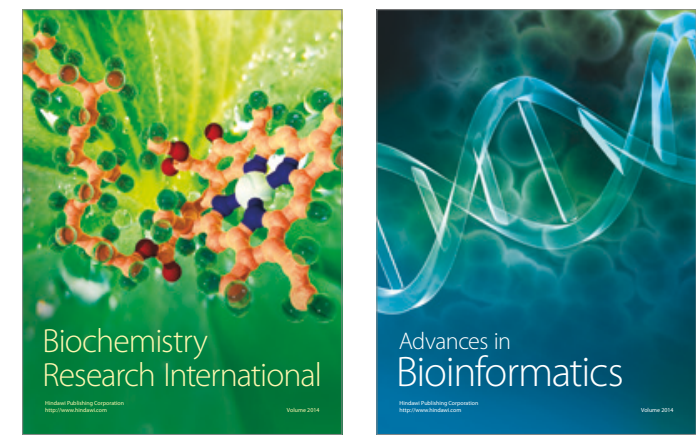

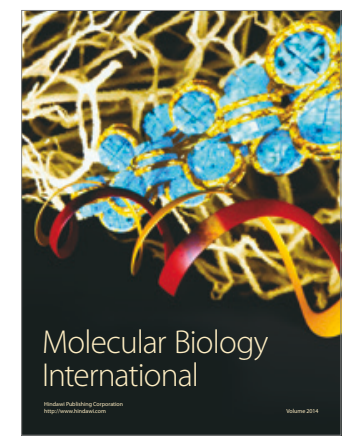

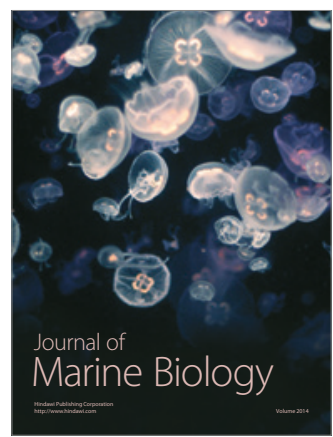

